\title{
PROPOSED VOLTAGE CONTROL METHOD OF BRUSHLESS DC GENERATOR FOR VEHICLE APPLICATION
}

\author{
Safaa A. Kalilah, Haitham Z. Azazy, Mervet A. Shanab and Fathy E. Abdel-Kader \\ Electrical Engineering Department, Faculty of Engineering, Shebin El-Kom, \\ Minoufiya University, Egypt
}

\begin{abstract}
Recently, brushless dc generator (BLDCG) becomes a very attractive alternative to its counterparts in many applications such as wind energy systems and transportation systems. That is because of its advantages which are high efficiency and energy density, light weight, compact design and low maintenance. The main problem has appeared in BLDCG applications which are characterized by large speed fluctuations like wind turbines and internal consumption engines. This speed variation leads to changes in the BLDCG output voltage. The goal of this study is keeping the generator output voltage constant with the speed variation of the prime mover using a simple control means includes a variable reactor. This work in BLDCG is presented for vehicle application, to be instead of the brush claw pole synchronous generator. Throughout the present work, a mathematical model of BLDCG is developed and used in computing the generator characteristics. An experimental setup is implemented for verifying the theoretical analysis. A comparison between the theoretical and experimental results confirms the validity of proposed analysis. The results show the good performance of BLDCG with the proposed simple control method.

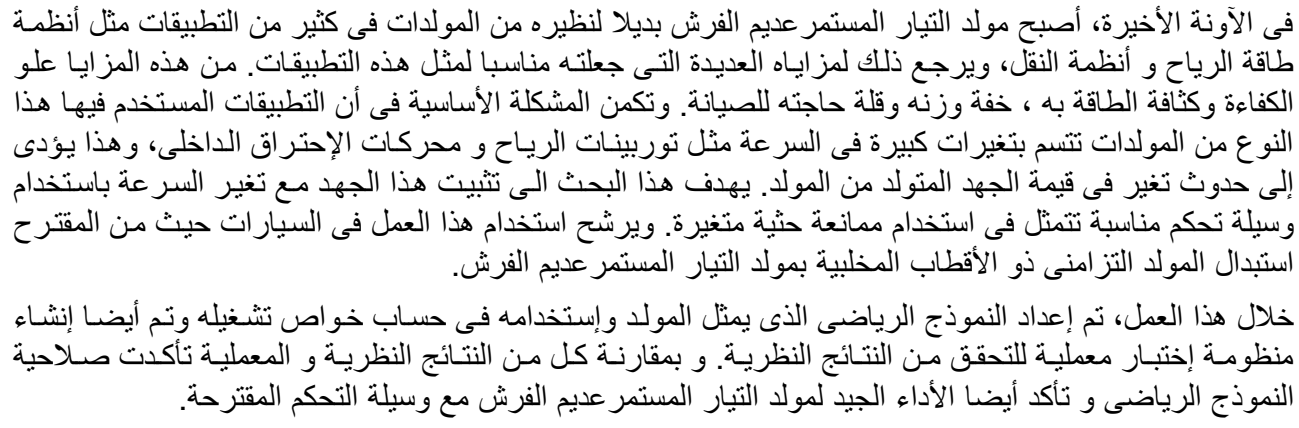

Keywords: BLDCG, Variable reactor, Variable Speed Generator, Wind Energy Generators.

\section{INTRODUCTION}

The idea of brushless dc machine had started in 1962 when T.G. Wilson and P.H. Trickey made a dc machine with an electronic commutator. This was an attempt to overcome the main drawback of brush dc machine, which represented in brushes and commutator segments and their need to frequent maintenance. The full realization of brushless machine became only possible in the early of 1980 s as a result of the availability of permanent magnet materials and reliable power electronic devices.

Brushless dc generator (BLDCG) has received a great attention over the past few decades, with a large number of publications reviewing their relevant merits. It has a stator with laminated steel to reduce the eddy current loss and a rotor provided with permanent magnets. Compared with the dc machine, the field windings, attached brushes and commutator segments are not required because of permanent magnets. As a result, the maintenance for those components is not necessary. In addition, the copper loss of the field winding is absent, therefore high efficiency is obtained. Because of those advantages, brushless dc generator has been candidate for many applications such as wind energy systems and transportation systems. These applications are characterized by large speed fluctuations accomplished with wind turbines and internal

Engineering Research Journal, Vol. 37, No.2, April 2014, PP: $1 \diamond \mathrm{V}-1 \mathrm{r}$. 
consumption engines. These large changes in the voltage. Some attempts have been reported in literature to overcome this problem [1-12].

The brushless dc (BLDC) machine is used as an integrated starter-generator-torque-booster (ISGTB) for hybrid electric vehicles [1-3]. It is operated in three modes of operation. Switch mode power converter, which consists of six-step inverter and bidirectional buck-boost converter, has supported all operating modes of ISGTB using intelligent control software. In generation mode, the amplitude of the induced emf is proportional to the speed of internal consumption engine which varies in large rate. This could be overcome by synchronizing the switching signals of the inverter switches with the generator terminal voltages and DC link voltage. While, the bidirectional Buck/Boost converter was introduced for adjusting the battery and DC link voltage levels to achieve all desired operation modes of the ISGTB.

A digital control technique for controlling the output voltage of BLDCG against shaft speeds using three phase controlled bridge has been proposed in [4-6]. The switching signals of the bridge devices are established using a digital controller called Field Programmable Gate Array (FPGA). The control technique was implemented using two power electronic control concepts: hysteresis current control and pulse width modulation (PWM) control. In both concepts, at any time, two phases of the machine windings are active and the third is silent.

A single stage step up/down AC/DC converter for small wind power BLDC generator has been presented in [7]. This converter consists of a three phase diode bridge rectifier and C'uk DC to DC converter. C'uk converter steps up and down the output dc voltage of the diode bridge to cope with the wind speed variation. This could be achieved by comparing the dc link voltage with a reference voltage then determining the duty ratio of the gating signal that switching on/off the MOSFET switch by PWM technique.

with each generator phase winding to suppress the increasing in voltage due to the speed by its voltage drop which varies also with the speed.

The variable reactor used in this work is the magnetic amplifier (MA) [13-15]. The MA is a type of magnetically controlled reactance. It consists of two windings on the outer two limbs of three limb iron core, connected in series with generator terminals. Auxiliary winding on the middle limb is connected to a controlled DC supply. Controlled current through the auxiliary winding is to control the saturation level of the outer limbs iron core. Hence, the inductance of the outer windings is controlled. The controlled current is obtained from the feedback control circuit of generator output voltage. A three phase diode bridge is connected to generator terminals after the reactors for rectifying the ac operating speed cause variations of BLDCG output In [8-10], a predictive control of BLDC generator coupled with wind turbine system has been proposed in a theoretical study. This method of control is applied to three phase controlled bridge to obtain a constant value of output dc voltage for connecting with dc grid. This was achieved using a digital control system based on minimization of joule losses and torque ripples.

A BLDC machine has been used as a motor and a generator in a certain application, it is a light motorcycle powered by fuel cell energy [11]. A typical BLDC motor drive system consists of the BLDC machine, the power inverter and the digital controller. In motoring mode, the digital controller energizes each phase of the BLDC motor in a sequence synchronizing with the rotor position in order to produce constant torque using 120 degree current conduction case. In other words, the machine works as a generator during regenerative braking. In this mode of operation, the dc link voltage decreases because of speed slowing down. As a result, boost converter is used to obtain a constant dc link voltage.

Variable-speed constant-frequency (VSCF) power converter has been described in [12]. This converter consists of a three phase diode bridge rectifier and three phase thyristor controlled inverter. The output voltage of the BLDCG is rectified by the diode bridge then converted to three phase ac voltage with fixed value and frequency for connecting to the ac grid using the inverter. This was achieved by comparing the actual dc link current, which varies with the prime mover speed, with a reference value of the current then the difference determines the firing angle of the thyristors.

All the previous attempts to overcome the BLDCG problem are complicated and costly. This paper presents a simple control means to obtain a fixed output dc voltage from the BLDCG over the prime mover speed range. This means is summarized in adding a variable reactor in series voltage. Figure (1) shows a schematic diagram of BLDCG setup. It is suggested, throughout this work, to replace the synchronous generator in vehicles by BLDCG along with its proposed control method.

In this paper a mathematical model for BLDCG with the proposed control method is developed and implemented to predict its performance characteristics at different operating conditions. An experimental setup is established for the setup to check the theoretical results. A comparison between the theoretical and experimental results is performed and evaluated. The results illustrate the good performance characteristics of BLDCG with the proposed control method. 


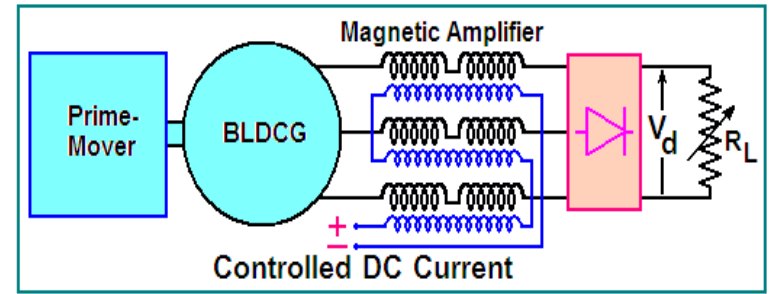

Fig. 1 A schematic diagram of BLDCG setup

\section{MATHEMATICAL ANALYSIS}

This paper is concerned with the study of steady state characteristics of BLDCG. The equivalent circuit of one phase of BLDCG with the controlled reactance $\left(\mathrm{X}_{\text {add }}\right)$ and resistive load $\left(\mathrm{R}_{\mathrm{L}}\right)$ is shown in fig. (2). The resistive load $\left(\mathrm{R}_{\mathrm{L}}\right)$, which is connected after the diode bridge, is not with the same value for each generator phase in the equivalent circuit. The equivalent load resistance for each generator phase $\left(\mathrm{R}_{\mathrm{Lph}}\right)$ is calculated by equating the power in $\left(\mathrm{R}_{\mathrm{L}}\right)$ with the power of $\left(3 \mathrm{R}_{\mathrm{Lph}}\right)$ as follows:

$\frac{3 V_{p h}{ }^{2}}{R_{L p h}}=\frac{V_{d}^{2}}{R_{L}}$

$V_{d}=1.35 V_{L L}=1.35 \sqrt{3} V_{p h}$

Where:

$\mathrm{V}_{\mathrm{d}}$ : the output dc voltage

$\mathrm{V}_{\mathrm{LL}}$ is the generator line to line voltage (before bridge)

$\mathrm{V}_{\mathrm{ph}}$ : the rms stator phase voltage

$\mathrm{R}_{\mathrm{L}}$ : the load resistance across bridge

$\mathrm{R}_{\mathrm{Lph}}$ : the equivalent load resistance per phase

By substituting from eq. (2) into (1), $\mathrm{R}_{\mathrm{Lph}}$ can be obtained

$R_{\text {Lph }}=\left(\frac{1}{1.35}\right)^{2} R_{L}$

The generator voltage equation per phase is expressed as:

$E=\left[\left(R_{a}+R_{\text {Lph }}\right)+J \omega\left(L_{a}+L_{a d d}\right)\right] I$

Where:

E: the rms stator phase e.m.f.

I: the rms stator phase current

$\mathrm{R}_{\mathrm{a}}, \mathrm{L}_{\mathrm{a}}$ : the stator phase winding resistance and self inductance

$\mathrm{L}_{\text {add }}$ : the inductance of added reactor per phase

The stator phase e.m.f. is described as a function of the operating speed (N) as follows:

$\mathrm{E}=\mathrm{K}_{\mathrm{v}} \mathrm{N}$

Where:

$\mathrm{Kv}$ : is the machine e.m.f. constant

Hence, the output power transferred to the load is calculated as:

$\mathrm{P}_{\text {out }}=3 \mathrm{I}^{2} \mathrm{R}_{\mathrm{Lph}}$
The total power losses $\left(\mathrm{P}_{\text {loss }}\right)$ in BLDCG can be expressed as

$\mathrm{P}_{\text {loss }}=\mathrm{P}_{\mathrm{i}}+\mathrm{P}_{\mathrm{m}}+\mathrm{P}_{\mathrm{cu}}$,

$\mathrm{P}_{\mathrm{cu}}=3 \mathrm{I}^{2} \mathrm{R}_{\mathrm{a}}$

Where :

$\mathrm{P}_{\mathrm{i}}$ : the iron losses

$\mathrm{P}_{\mathrm{m}}$ : the mechanical losses

$\mathrm{P}_{\mathrm{cu}}$ : the copper losses

Then the input power and, consequently, efficiency are obtainable.

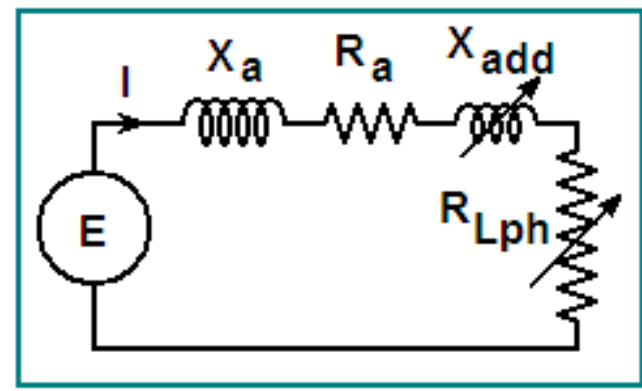

Fig. 2 BLDCG equivalent circuit per phase

\section{THEORITICAL RESULTS}

A computer program has been established based on the proposed mathematical model to study the steady state characteristics of BLDCG. The results are presented as follows.

3.1. Characteristics with Adding a Series Reactor

The effect of adding a reactor (without control) in series with each generator phase winding on the performance characteristics of BLDCG is illustrated in figures (3-5). Figure (3) shows the output dc voltage $\left(\mathrm{V}_{\mathrm{d}}\right)$ at different values of the added reactor inductance with the same load resistance $\left(R_{L}=5 \Omega\right)$. It is observed that by increasing the value of added inductance $\mathrm{V}_{\mathrm{d}}$ decreases. This is because of increasing the reactor voltage drop which is subtracted from the stator phase e.m.f to obtain the output voltage. It is observed that, adding a constant reactance achieves a constant value of output voltage through the high speed range. For obtaining the same constant voltage over the low speed range, the inductance should be controlled.

The output dc voltage is predicted also at different values of load resistance with the same reactor inductance $\left(\mathrm{L}_{\mathrm{add}}=0.0303 \mathrm{H}\right)$ as shown in fig. (4). It is noticed that $V_{d}$ increases by increasing the load resistance due to reducing the load current and, consequently, the generator phase current reduction. It is also shown that, when the added reactor inductance $\left(\mathrm{L}_{\mathrm{add}}\right)$ equals $0.0303 \mathrm{H}$, a value of the output dc voltage $(14 \mathrm{~V})$, which is suitable for charging the vehicle battery as will be illustrated later, is obtained at a load resistance $\left(\mathrm{R}_{\mathrm{L}}=5 \Omega\right)$. 
Figure (5) shows the variation of the generator voltages with speed at no load, load resistance of $\left(\mathrm{R}_{\mathrm{L}}\right.$ $=5 \Omega$, with and without adding a reactor of inductance $\left(\mathrm{L}_{\mathrm{add}}=0.0303 \mathrm{H}\right)$. The output dc voltage $\left(\mathrm{V}_{\mathrm{d}}\right)$ at no load is higher than the generator phase e.m.f. (E) by the ratio of equation (2). When the generator is loaded, $V_{d}$ is decreased due to voltage drop on $\mathrm{R}_{\mathrm{a}}$ and $\mathrm{X}_{\mathrm{a}}$. A constant output dc voltage is obtained when the reactor is added. This is explained by the variation of the voltage drop on the added reactor $\left(\mathrm{V}_{\mathrm{XL}}\right)$ with speed.

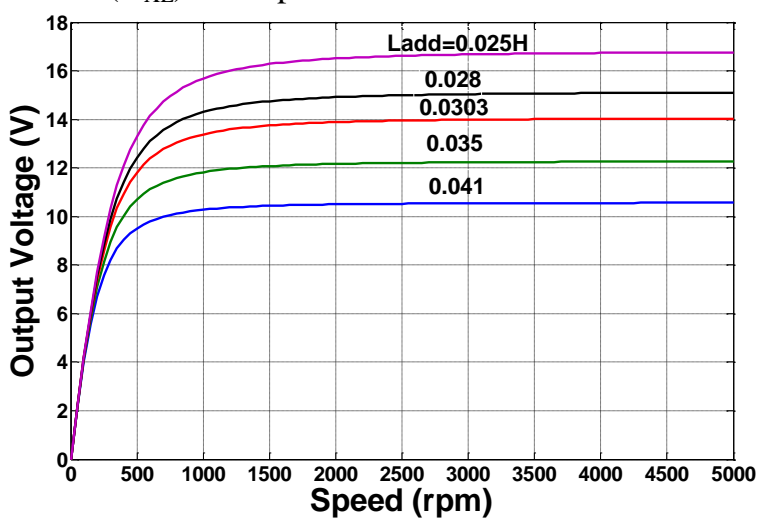

Fig. 3 Output dc voltage with speed at different values of added inductance and $\mathrm{R}_{\mathrm{L}}=5 \Omega$.

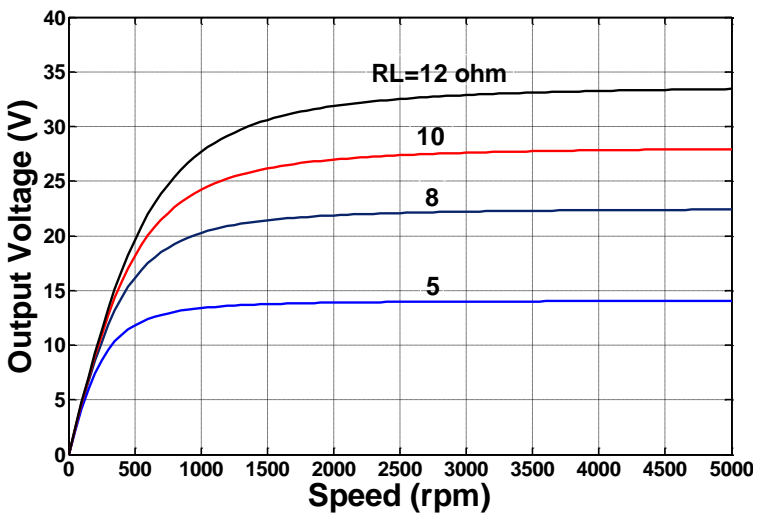

Fig. 4 Output dc voltage at different values of load resistance and Ladd $=0.0303 \mathrm{H}$.

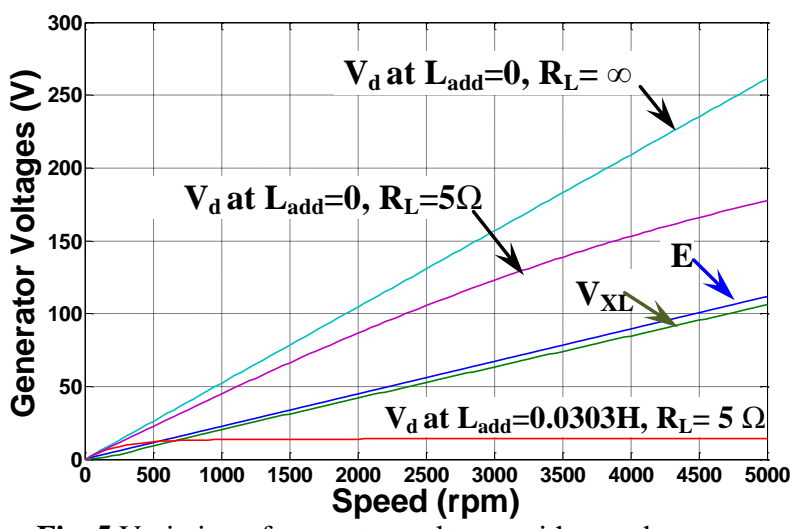

Fig. 5 Variation of generator voltages with speed at no load, $\mathrm{R}_{\mathrm{L}}=5 \Omega$, with and without added reactor.

\subsection{Characteristics for Output of $\mathbf{1 4} \mathrm{V}$}

As stated before in part (I), the BLDCG studied throughout this work, is recommended to be an alternative to the claw pole synchronous generator in vehicles. The generator in the vehicle is used to charge a battery of $12 \mathrm{~V}$, therefore the suitable voltage for charging is $14 \mathrm{~V}$.

The generator characteristics are studied for output dc voltage of $14 \mathrm{~V}$ with a suitable resistance of $6.667 \Omega$ which is actually tested experimentally. The results are illustrated by figures (6-9) .

Figure (6) shows the desired output dc voltage (14V) as a function of speed at certain load resistance and added reactor inductance. The voltage is constant over a high speed range due to the effect of added reactor. But it decreases at low speeds. This requires changing the reactor inductance with the speed variation to obtain the desired voltage at different speeds. The output dc load current at the same load resistance and added reactor inductance is shown in fig. (7). The current follows the shape of the output voltage.

The input and output powers as function of speed at the same load resistance and added reactor inductance are shown in fig. (8). Both input and output powers are constant over most of speed range. The efficiency/speed curve is also nearly constant over most of speed range as shown fig. (9). The efficiency has small values because the BLDCG rating is small.

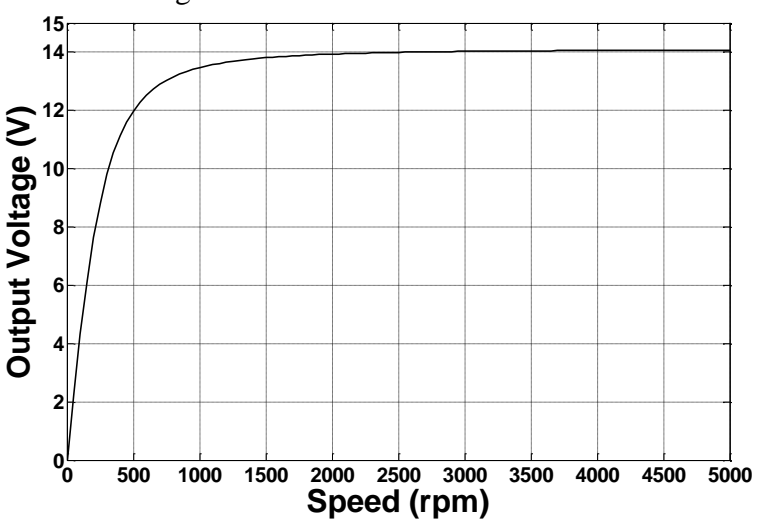

Fig. 6 Output dc voltage with speed at $R_{L}=6.667 \Omega$ and Ladd $=0.041 \mathrm{H}$.

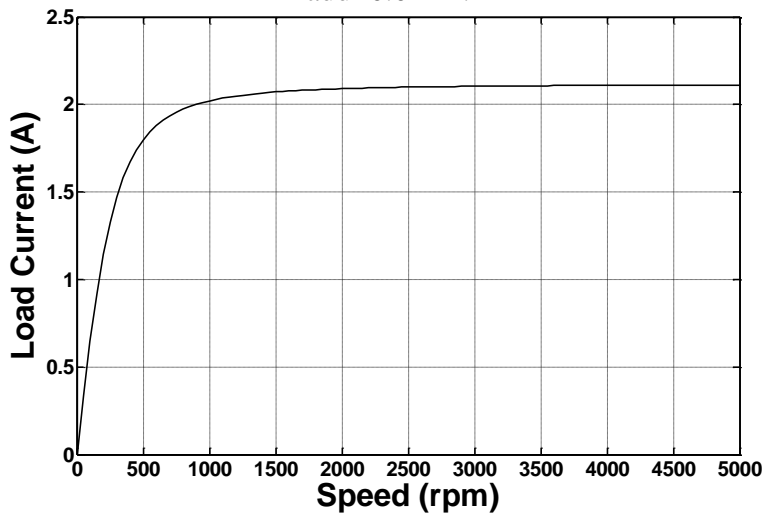

Fig. 7 Output dc current with speed at $R L=6.667 \Omega$ and Ladd $=0.041 \mathrm{H}$. 


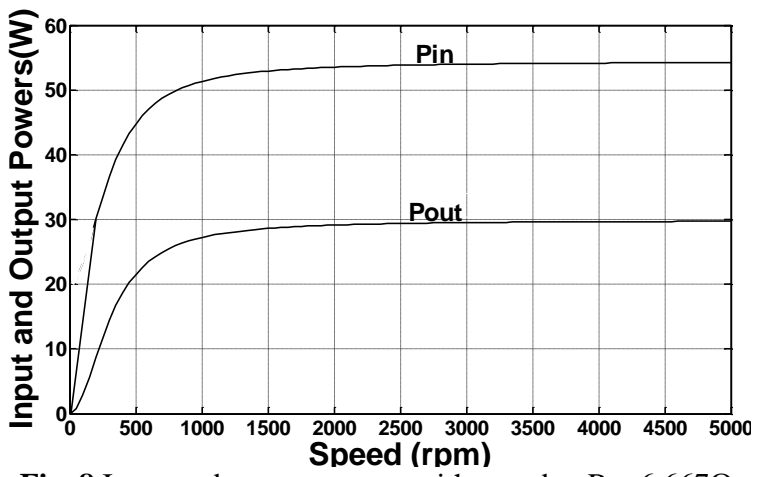

Fig. 8 Input and output powers with speed at $R_{L}=6.667 \Omega$ and Ladd $=0.041 \mathrm{H}$.

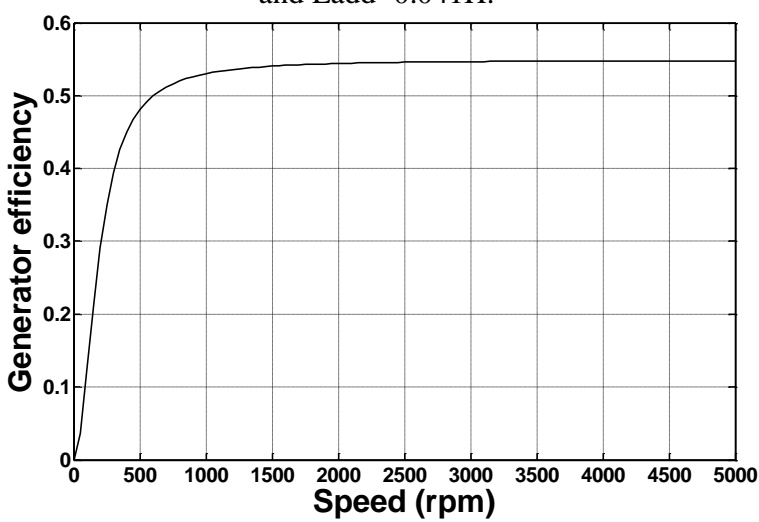

Fig. 9 Generator efficiency with speed at $R_{L}=6.667 \Omega$ and Ladd $=0.041 \mathrm{H}$.

\section{EXPERIMENTAL RESULTS}

The experimental setup has been established for BLDCG as shown in fig. (10), to verify the validity of theoretical analysis. The setup consists of the generator under test (BLDCG) with rating $(150 \mathrm{~W}$, 10.7A, $14 \mathrm{~V}, 3900 \mathrm{rpm})$. An induction motor of $1 \mathrm{hp}$, $380 \mathrm{~V}, 1425 \mathrm{rpm}$ is used as a prime mover. Three magnetic amplifiers (MA) each of them is connected in series with each generator phase winding. The speed of induction motor is controlled by a digital frequency converter. The reactor inductance is controlled by the controlled dc current passes through the MA auxiliary winding, to give the desired output voltage $(14 \mathrm{~V})$. The auxiliary windings of the three magnetic amplifiers are connected in series to a variable dc voltage source, consists of a variac and a diode bridge. The experimental results are obtained at constant output dc voltage of $14 \mathrm{~V}$, over a speed range from 450 to $1350 \mathrm{rpm}$. Higher speeds are experimentally limited due to the mechanical fixation.

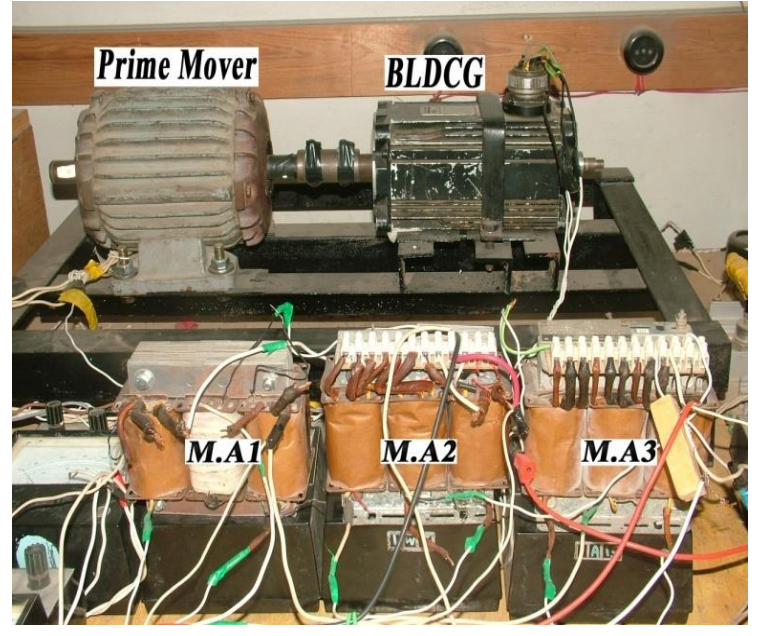

Fig. 10 Main parts of BLDCG experimental setup

Figure (11) shows the desired output dc voltage $(14 \mathrm{~V})$ during the speed variation, with the load resistance $\left(\mathrm{R}_{\mathrm{L}}\right)$ of $6.667 \Omega$ and the controlled reactor. This desired voltage is obtained by manually changing the reactor inductance through the variation of the magnetic amplifier control current. Values of reactor inductance are experimentally determined at different speeds as shown in fig. (12). The variation of controlled current of the magnetic amplifier is shown in fig. (13). The variation of reactor terminal voltage per phase is shown in fig. (14).

The output dc current is constant at 2.1 A during the range of speed variation (from 450 to $1350 \mathrm{rpm}$ ). Also, the output power is constant at $29.4 \mathrm{~W}$ during this range of speed variation.

The input power variation with speed is shown in fig. (15). The input power is increased during speed increasing due to the increasing of mechanical and stray losses.

Accordingly, the efficiency/speed curve is determined over the tested speed range in fig. (16). It is observed that Efficiency is decreased with speed as a result of losses' increasing.

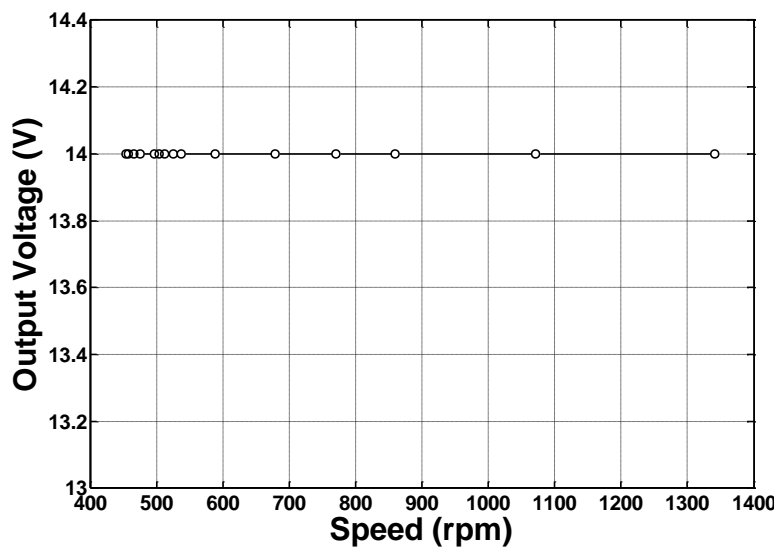


Fig. 11 Output de voltage at $R_{L}=6.667 \Omega$ and controlled inductance.

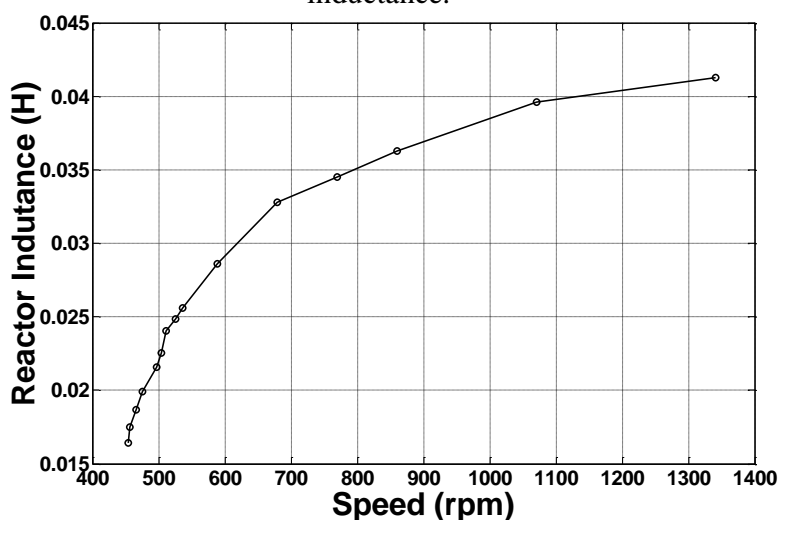

Fig. 12 Necessary inductance variation with speed for constant output voltage at $R_{L}=6.667 \Omega$.

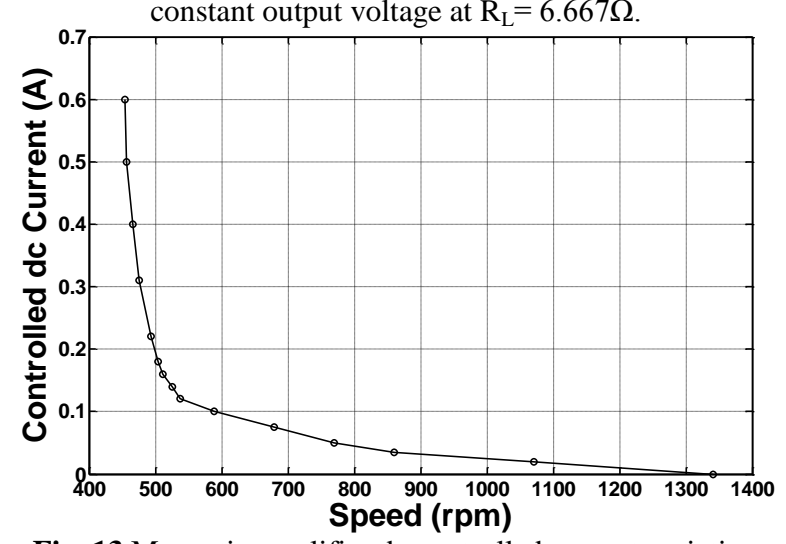

Fig. 13 Magnetic amplifier dc controlled current variation with speed for constant output voltage at $R_{L}=6.667 \Omega$.

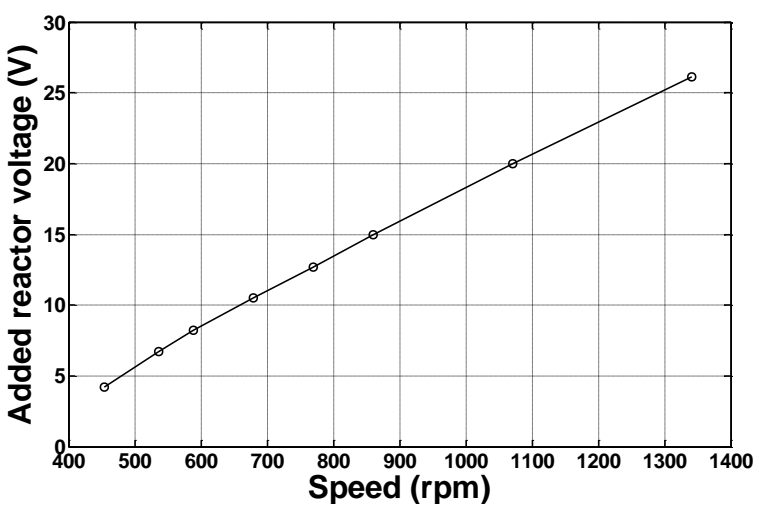

Fig. 14 Reactor voltage variation with speed at $R_{L}=6.667 \Omega$ and controlled inductance.

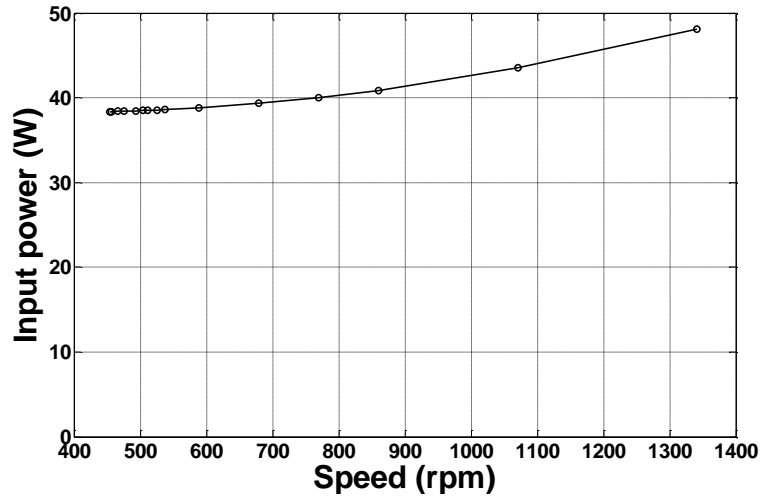

Fig. 15 Input power variation with speed at $R_{L}=6.667 \Omega$ and controlled inductance.

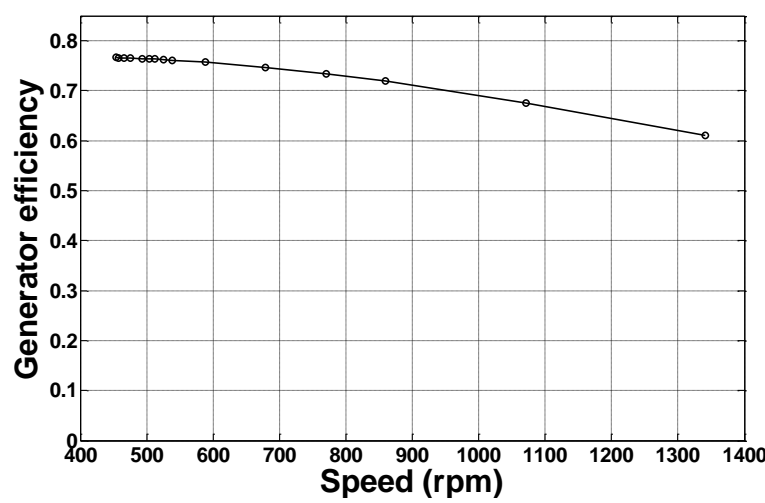

Fig. 16 Generator efficiency variation with speed at $R_{L}=$ $6.667 \Omega$ and controlled inductance.

\section{CONCLUSION}

A BLDC generator has been proposed as an alternative to synchronous generator in vehicles. A variable reactor is connected in series with each generator phase winding for suppressing the variation of output voltage with prime mover speed. The developed mathematical model has accurate results to evaluate the generator performance. Good agreement is obtained between experimental and theoretical results. BLDCG with the proposed control method achieves a constant desired voltage over a wide range of speed variation.

\section{REFERENCES}

[1] P. Bajec, B. Pevec, D. Voncina, D. Miljavec and J. Nastran, "Extending the Low-Speed Operation Range of PM Generator in Automotive Applications Using Novel AC-DC Converter Control" IEEE Transactions on Industrial Electronics, Vol. 52, No. 2, pp 436-443, April 2005

[2] P. Bajec, B. Pevec, D. Voncina, D. Miljavec and J. Nastran, "Novel AC-DC Converter Control Principle for Automotive BLDC Generator in Low-Speed Range”, 'Advanced Motion Control', 
8th IEEE International Workshop, AMC'04, pp 105-110, 25-28 March 2004

[3] P. Bajec, D. Voncina, D. Miljavec and J. Nastran, "Bi-directional Power Converter for Wide Speed Range Integrated Starter-Generator", IEEE International Symposium on Industrial Electronics, Vol. 2, pp 1117-1122, May 2004.

[4] N. Milivojevic, M. Krishnamurthy, A. Emadi, and I. Stamenkovic," Theory and Implementation of a Simple Digital Control Strategy for Brushless DC Generators", IEEE Transactions on Power Electronics, Vol. 26, No. 11, pp 3345-3356, Nov 2011.

[5] N. Milivojevic, I. Stamenkovic, M. Krishnamurth and A. Emadi, "A Digital Control Strategy for Brushless DC Generators", 'Applied Power Electronics and Exposition' 25th Annual IEEE Conf., APEC'10, pp 1957-1962, 21-25 Feb 2010.

[6] N. Milivojevic, M. Krishnamurthy, Y. Gurkaynak, A. Sathyan, Y. J. Lee and A. Emadi, "Stability Analysis of FPGA-Based Control of Brushless DC Motors and Generators Using Digital PWM Technique", IEEE Transactions on Industrial Electronics, Vol. 59, No. 1, pp 343-351, Jan. 2012.

[7] C.T. Pan , T.Y. Chang and E. Fang,"A Novel Single Stage Step Up/Down AC/DC Converter for Small BLDC Wind Power Generators", 'Power Electronics and Drive Systems' IEEE 9th International Conf (PEDS),pp 861-866, 5-8 Dec 2011.

[8] G. Gatto, I. Marongiu, A. Perfetto and A. Serpi, "Brushless DC Generator Controlled by Predictive Algorithm”, 'Clean Electrical Power' International Conf., pp 727-732, 9-11 June 2009.

[9] G. Gatto, I. Marongiu, A. Serpi and A. Perfetto,"Predictive Control of Standalone Brushless DC Generators", 'Electronics, Circuits, and Systems', 16th IEEE International Conf., ICECS'09, pp 896-899, 13-16 Dec 2009.

[10] G. Gatto, I. Marongiu, A. Perfetto and A. Serpi, "Brushless DC Generator controlled by Constrained Predictive Algorithm", 'Industrial Electronics', IEEE International Symposium, ISIE'10, pp 1224-1229, 4-7 July 2010.

[11] T. Kim and J. Yang, "Control of a Brushless DC Motor/Generator in a Fuel Cell Hybrid Electric Vehicle", IEEE International Symposium on Industrial Electronics', ISlE '09, pp 1973-1977, 58 July 2009.

[12] R. Knshnan and G. RIM, "Modeling, Simulation, and Analysis of Variable-Speed Constant Frequency Power Conversion Scheme with a Permanent Magnet Brushless dc Generator", IEEE Transactions on Industrial Electronics, Vol. 31, No. 4, pp 291-296, Aug 1990.
[13] L. Austrin, D. Ribbenfjärd and G. Engdahl "Simulation of a Magnetic Amplifier Circuit Including Hysteresis", IEEE Transactions on Magnetics, Vol. 41, No. 10, OCT. 2005, pp 3994-3996.

[14] J.-U. W. Hsu, A. P. Hu, A. Swain, X. Dai and Y. Sun, "A New Contactless Power Pick-Up with Continuous Variable Inductor Control using Magnetic Amplifier" 'Power System Technology' International Conf., PowerCon '06, 22-26 Oct. 2006, pp 1-8.

[15] L. Austrin, E. F. Karlstrom and G. Engdahl "Evaluation of Switching Losses in Magnetic Amplifiers as an Alternative to IGBT Switching Technologies", 'Power Electronics, Machines and Drives', 4th IET Conf., PEMD '08, 2-4 April 2008, pp 250-254. 